\title{
NUEVAS FUENTES DE INFORMACIÓN Y MALA PRAXIS PERIODÍSTICA
}

\author{
Rufino Sánchez-Sánchez ${ }^{1}$. Universidad Complutense de Madrid. España \\ rufino.sanchez@rtve.es
}

\section{RESUMEN}

No sé cómo trabajábamos antes sin Internet" Es una frase que los periodistas escuchamos (y pronunciamos) constantemente. Nos resulta tan habitual utilizar la Red como fuente de información que apenas recordamos cómo trabajábamos cuando no estaba a nuestro alcance. El Consejo de Informativos de Radio Nacional de España ya se ha planteado la necesidad de debatir acerca de la conveniencia de usar redes sociales de Internet (del estilo de facebook o twitter) como fuente de información, afirmando que "no son estrictamente una fuente, sino un canal a través del cual acceder a fuentes, particulares o institucionales" y que por lo tanto hay que extremar el cuidado en el uso de la información que nos llegue por estas vías. Es lógico que se estudien con detenimiento las nuevas realidades comunicativas teniendo en cuenta los problemas que Internet como fuente de información provoca en los medios de todo el mundo. La red altera el tradicional esquema "Fuente- Periodista-Lector" y democratiza el papel de emisor de la comunicación colocando a los periodistas en una posición crucial: es el momento de defender la profesionalidad, la deontología profesional y las normas clásicas del periodismo.

PALABRAS CLAVE: Internet - Fuente de información - Redes sociales - Deontología - Error

\footnotetext{
1 Autor correspondiente

Rufino Sánchez-Sánchez: Universidad Complutense de Madrid. España

Correo: rufino.sanchez@rtve.es
} 


\title{
NEW INFORMATION RESOURCES AND BAD JOURNALISTIC PRACTICE
}

\begin{abstract}
I don't know how we worked before Internet" Is something that journalist use to listen (and to declare) often. Using the World Wide Web is so habitual that we don't remember how we were working when it isn't exists. Board of informatives of National Radio of Spain has appeared the need to debate about convenience of using social networks (like facebook or twitter) as information research saying they "are not strictly a source, but a channel across which to accede to particular or institutional sources" and therefore it is necessary to have a very special care with the information that comes to us across these routes. It is natural that the new communicative realities are studied thoroughly because Internet as information research cause a lot of problems in media all around the world. It transforms the traditional scheme "Source-Journalist-Public" and democratizes the issuer's paper of the communication placing to journalists in a crucial position: it is the moment to defend the professionalism, the business ethics and the classic journalistic practice.
\end{abstract}

KEY WORDS: Internet - Information research - Social networks - Business ethics Mistake

\section{INTRODUCCIÓN}

Los periodistas estamos asustados. Asustados por todos aquellos gurús de los nuevos tiempos que vaticinan el final de nuestra profesión. "Las nuevas tecnologías lo hacen posible, ha muerto el periodista, cualquiera puede hacer su trabajo" dicen a todas horas. "Cualquiera" puede encargarse de elaborar, editar, publicar y difundir información en nuestra nueva sociedad gracias a Internet. Ahora entendemos a los angustiados obreros ingleses que abrazaron el ludismo en tiempos de la Revolución Industrial arremetiendo contra las máquinas que, literalmente, les dejaban en el paro. La historia se repite. Aquel movimiento gozó de corta (pero intensa) vida. Alguien terminó dándose cuenta de que el problema no eran las nuevas tecnologías, sino quienes las aplicaban.

Como periodistas estamos obligados a reflexionar. ¿Cómo hemos integrado las nuevas tecnologías en nuestro día a día? ¿Son herramientas que enriquecen nuestro trabajo o las usamos sin aplicar criterios de calidad o filtros éticos sólo porque nos facilitan la vida? ¿Nos hemos preguntado alguna vez si podemos usar la información que encontramos en la World Wide Web en nuestro trabajo? ¿Alguien ha reflexionado al respecto? 


\section{¿Estamos en crisis?}

El fantasma de la crisis está cada día más presente en las redacciones. Muchos son los que buscan sus orígenes en los avances tecnológicos que tantos cambios han traído a la esencia de la comunicación. Crisis estructural, o tecnológica, crisis económica (y laboral) y, sobre todo, crisis de imagen. De prestigio entre el público. La obsesión por el sensacionalismo, el servilismo político, la necesidad de impresionar al público, la pérdida de pluralismo, el uso de fuentes sin contrastar... son algunas de las razones por las que el público parece no confiar en los medios de comunicación.

Quizá esta realidad se encuentra detrás del nacimiento de ese fenómeno extraño que a nadie pone de acuerdo, que tanto enfada a los profesionales de la comunicación (en parte, con razón) y que hay quién se empeña en presentar como el futuro de la información: el periodismo ciudadano. Mientras la primera versión de los sitios online evolucionaba hasta la web 2.0, mucho más interactiva que los primeros modelos, las "guerras" libradas por Internet pasaban de la trinchera "medios tradicionales vs. medios online" a una menos tecnológica y más humana "periodistas vs. ciudadanos que desean ejercer de periodistas". Explica James Curran que, aunque en ocasiones blogs y páginas de periodismo "alternativo" han sacado a la luz noticias interesantes, e incluso escándalos políticos lo cierto es que su capacidad de alcanzar al gran público es, por definición, muy limitada "En Gran Bretaña, el 79 por ciento de los usuarios de Internet no ha leído un solo blog en los últimos 3 meses (Oficina Nacional de Estadística)" y a pesar de todo confía en la colaboración con "reporteros aficionados" (Curran, 2010)

\section{DESARROLLO}

\subsection{Nuevas servidumbres}

Hay quien asegura que de nuestra profesión, con Internet, cambia, incluso, el nombre con el que deberíamos referirnos a ella. Pero es, sin duda, esta supuesta democratización del papel de emisor comunicativo el elemento que más influye y condiciona la profesión periodística. Las nuevas tecnologías facilitan la distribución de la información pero debemos insistir y mantener que el periodismo es mucho más que todo eso. En honor a la verdad hay que agradecerle a Internet que haya derribado alguna de las limitaciones clásicas del periodismo. Una página web no tiene hora de cierre ni sufre problemas de espacio. Ahora su problema es otro:

El desarrollo de las nuevas tecnologías y la generalización del uso de Internet en tantos países del mundo han alterado el concepto tradicional de la periodicidad y nos llevan a un futuro próximo de instanteneidad que supera el día o la semana, y que será (ya lo es, en cierta medida) una de las características de la noticia en la sociedad cibernética que se va implantando: tener acceso a los hechos cuando están ocurriendo o acaban de suceder (Edo, 2003, p. 76-77) 
Internet es esclavo de la inmediatez. Hay que publicar la noticia antes que nuestros competidores, como mucho, al mismo tiempo. Por eso la mayoría de las entradas de un diario online proceden de notas de agencia: se toma el teletipo, se copia literalmente, se publica... y apenas transcurren unos segundos desde que la agencia distribuye una noticia a los medios hasta que ésta se encuentra a disposición del público. ¿Resultado? el porcentaje de información errónea que llega al lector aumenta considerablemente.

Presentamos un caso especialmente llamativo. El 9 de Octubre de 2007 las redacciones digitales de El Mundo, ABC y Público fueron víctima precisamente de lo que estamos comentando. Un teletipo de la agencia Europa Press recibido minutos antes de las 14 horas de la tarde aseguraba que el escolta de un edil del Partido Socialista de Euskadi había fallecido tras la explosión de un coche bomba en el barrio de La Peña, en Bilbao. A las 13:59 la edición digital de ABC titula "Muere en un atentado con coche bomba en Bilbao el escolta de un concejal del PSE-EE", incluyendo, además, el vínculo al dossier especial "ETA pone fin a la tregua" que, indudablemente, había preparado la redacción mucho antes del atentado del día 9. Un minuto después Público.es también se hace eco de la noticia: "El escolta de un concejal del PSE muere por la explosión de un coche bomba en Bilbao" y a las 14:05 la página web de El Mundo incluye el siguiente titular bajo una llamativa caja de texto de color rojo con la palabra "Urgente" escrita en su interior: "Muere un escolta al estallar una bomba en Bilbao".

El desdichado escolta protagonizó titulares on line durante 8 minutos hasta que la agencia corrigió su nota advirtiendo que no había fallecido, sino que había resultado herido. El artículo que el diario digital 20minutos.es dedicó a la noticia esa misma tarde explicaba con detalle el estado en el que Gabriel Ginés, el escolta herido, había ingresado en el hospital de Cruces a las 14:15 de la tarde:

Con quemaduras de segundo grado en la cara y de tercer grado en la mano, además de una herida en la espalda. Fuentes médicas han explicado que presenta quemaduras en el $4 \%$ de su cuerpo y que en todo momento ha estado consciente. Los médicos no temen por la vida del escolta, cuya herida más grave es la de la mano (20MINUTOS, 2007)

Bastante distinto de la macabra realidad que nos habían anunciado el resto de medios, eso sí, con tanta rapidez que el escolta aún no había llegado al hospital pero ya tenía plaza en la morgue. No podemos culpar a Internet de este error, pero sí decir que es responsable indirecto de su rápida distribución. 


\subsection{Fuentes de des-información}

Un estudio de Fundación Telefónica analiza el uso de fuentes de información por parte de medios impresos y digitales. Las normas tradicionales respecto a su uso establecen que no sólo hay que contrastar la información con fuentes fiables, también hay que dejar claro en nuestros textos, en la medida de lo posible, cuales son dichas fuentes.

Sin embargo, en la mayoría de los artículos analizados de Medios Impresos no podían reconocerse las fuentes consultadas para la elaboración de los mismos, más de un 20\%; Si a eso sumamos el porcentaje del 15\% de artículos "sin atribución expresa", nos encontramos con una extensa laguna de un 35\% de imprecisión en cuanto a fuentes se refiere. Las instituciones políticas son consultadas en un $13 \%$ de las ocasiones y las fuentes directas proporcionan información en el 12\%. Si preocupantes son los datos referidos a Medios Impresos, no menos lo son los de los Medios Digitales: las agencias de información son la fuente de información predominante, en un 47,5\% de los casos. El 35\% de la información que se publica en los medios online no tiene fuentes, a lo que hay que sumar un $2 \%$ más "sin atribución expresa". Apenas un $4 \%$ de las noticias publicadas en medios digitales se basa en información proporcionada por Instituciones políticas y otros medios de comunicación. (Diezhandino, 2007)

La conclusión es que este nuevo modelo informativo que pretende salvar y reformar al tradicional es un periodismo de mesa cuyo trabajo, en la mayoría de los casos es la trascripción literal, el corta-pega, y cuando no es así olvida sus obligaciones para con las fuentes y los lectores.

Existe un punto y aparte en Radio Televisión Española respecto al trabajo con materiales procedentes de Internet. Tuvo lugar el 13 de enero de 2010. En la $2^{a}$ edición del Telediario de la primera cadena (el que se emite a las 21 horas) se cometieron dos graves equivocaciones. La primera relacionada con el terreno de Haití. El informativo abría con imágenes de la catástrofe (sin concretar su procedencia) (RTVE, 2010, minuto 0.10) y poco más tarde se dedicaba una noticia entera a los primeros momentos del seísmo tal y como los habían vivido las víctimas. Es en este momento cuando se hace mención indirecta a la procedencia de las imágenes: "Es el momento del terremoto, en este vídeo de aficionado se aprecia como una construcción se desploma por completo, y el terrible estruendo" (RTVE, 2010, minuto 7.56)

"El momento del terremoto" como aseguraba la redactora en su información, era, en realidad una tormenta en Venecia, y la "construcción que se desploma" parte de la estructura que conformaba el escenario de un festival musical celebrado en la ciudad italiana. (EL PAÍS, 2010) 
Los responsables informativos cometerían un error similar apenas unos minutos más tarde: "Es el puente que unía los pueblos de Viso y San Lorenzo de Calatrava, en Ciudad Real" de esta manera se presentan imágenes procedentes de un "vídeo doméstico" grabado durante las riadas "que hace dos semanas se lo llevaron por delante, el agua arrastra la tierra, rompe el asfalto y hace desaparecer, finalmente, como ven, la carretera" (RTVE, 2010, minuto 40.34) La gran pega del vídeo es que la tierra "arrastrada", el asfalto "roto" y la carretera "desaparecida" no se encontraban en la provincia de Ciudad Real, sino en Estados Unidos. (EL PAÍS, 2010)

Al día siguiente llegaría el momento de las rectificaciones:

La dirección de TVE lamenta enormemente este error y pide disculpas por ello. Mientras se investiga el hecho, se ha reactivado el protocolo de máximo contraste cuando se utilizan imágenes vertidas en la Red (RTVE, 2010)

Una idea que nos llama la atención es la de que la dirección de TVE haya activado "el protocolo de máximo contraste", que, a pesar de su sonoridad, no es una misión secreta de James Bond sino el recordatorio al personal de la casa de algo que en realidad no debería hacer falta recordar porque es una norma básica del periodista: hay que contrastar la información de nuestras fuentes, mucho más en caso de orígenes dudosos o materiales hallados en Internet.

"Accuracy, accuracy, accuracy" (exactitud, exactitud, exactitud) Esas eran las tres normas básicas que todo periodista debía seguir en su trabajo según Joseph Pulitzer. Melvin Mencher lo recuerda y las recomienda, además, para evitar querellas y demandas. (Mencher, 2003) Pero no hay que pensar sólo en problemas legales, ser riguroso en nuestro trabajo es una cuestión de pundonor profesional y respeto al público. ¿Qué debemos hacer si a pesar de contrastar o precisamente por no hacerlo cometemos errores? Ser consecuentes y reconocerlos. Es lo que espera el público de nosotros, según la Asociación Norteamericana de Editores de Periódicos: "El 63\% de los lectores aseguran sentirse mejor respecto a la calidad de la información si ven correcciones" concluyen, "Si hay un error, admítanlo". La gente lo prefiere, aseguran, "No lo esconda, déjeles saber que usted quiere que sepan que se equivoca" (ASNE, 1998)

Vamos a hacerles caso y a reconocer un error personal. Tiene que ver con la exigencia de inmediatez informativa y el uso de Internet como fuente de información. Los periodistas disponemos cada vez de menos tiempo para contrastar nuestra información. Sobre todo en el caso de una noticias improgramadas, que son aquellas que se nos presentan de manera imprevista, y que ha de distribuirse enseguida. (Tuchman, 1983) 
Por ejemplo, los fallecimientos de personajes públicos. Un campo en el que tengo experiencia. En los últimos años he cubierto para el área de actualidad y magazines de Televisión Española la muerte de actores, productores y directores españoles como Luís García Berlanga, José Luís López Vázquez, Antonio Ozores, María Isbert... y elaborado reportajes sobre artistas extranjeros como Elizabeth Taylor, Paul Newman o Michael Jackson.

Minutos después de conocerse todos y cada uno de estos fallecimientos los diarios digitales tienen la noticia en portada. Fallecimiento y biografía del personaje. Ambos elaborados por la agencia EFE. La necesidad de inmediatez es tal que ningún medio desea descolgarse de los demás, todos ellos necesitan informar a los internautas, aunque sea con una noticia de agencia, mientras sus redactores elaboran su propia información. Televisión y Radio también nos contagiamos de esa necesidad de inmediatez.

El día que falleció Auguto Algueró agencias y prensa digital destacaban su faceta como compositor de música ligera. "El padre de la chica ye-ye" titulaban en la web de la revista Fotogramas. Y el resto de medios desgranaban la lista de sus canciones: "Tómbola", "Trébole", "Penélope", "Estando contigo" y "Vivo cantando". Nosotros también lo hicimos, en el programa “Corazón" de ese día (RTVE, 2011/1, minuto 5.00) Minutos después de la emisión recibíamos un correo electrónico de Carmen Alcalde, hija de Aniano Alcalde, verdadero creador de "Vivo Cantando".

La canción que interpretó Salomé en el Festival de Eurovisión no era obra de Augusto Algueró. El compositor simplemente fue responsable de los arreglos para su puesta en escena. Lógicamente se produjo una rectificación: (RTVE, 2011/2, minuto 5.30) Atribuir "Vivo cantando" a Augusto Algueró es una equivocación que cometimos casi todos los medios de comunicación que utilizamos Internet como fuente de información aquel día. ¿El origen del error? Imposible averiguarlo, porque en Internet, como afirma Pablo Boczkowski, se produce un proceso de "clonado" de la información. (Boczkowski, 2010)

Y este proceso de "clonado" tiene como consecuencia un progresivo empobrecimiento de los contenidos. En primer lugar por ser redundantes, en segundo, porque además de plagiarse las ideas originales y los datos exactos, se plagian los falsos:

La visibilidad que ofrece la edición continua reduce al mínimo el tiempo de la novedad y conduce a sorprendentes semejanzas, tanto en los enunciados como en el desarrollo de la información, de medios que compiten entre sí. [...] Se rompe así el carácter exclusivo de las primicias, los scoops periodísticos, y aumenta, fruto de la observación de los medios entre sí, el clonado de los aciertos y errores, esto es, la sedimentación noticiosa redundante (Díaz Nosty, 2011) 
El fenómeno del "clonado" que mencionan Pablo Boczkowski y Bernardo Díaz Nosty se hace especialmente evidente entre los blogs, sobre todo cuando éstos quieren imitar a los medios de comunicación. Apenas unos minutos después de que el teletipo de Agencia EFE informase a las redacciones acerca del fallecimiento del actor Juanito Navarro, ya podía leerse la noticia en todos los medios digitales (y al igual que sucedió con la muerte de Augusto Algueró, todos publicaron el despacho de EFE íntegro hasta que elaboraron uno propio) Poco después un malintencionado internauta modificaba el artículo del actor en la página web Wikipedia, adjudicando a Juanito la paternidad de un popular periodista y presentador español: Pepe Navarro

En esta ocasión el error era bastante más evidente, al menos para los periodistas, ningún medio (digital o no) cayó en la trampa. Quienes sí lo hicieron, en cambio, fueron los bloggers, ellos no sólo se fiaron de la información de Wikipedia, sino que utilizaron su texto redactado, lo copiaron, y lo pegaron en sus blogs. Una poderosa razón para defender el tratamiento profesional de la información y un argumento más a la hora de pedir prudencia a los comunicadores respecto al material que podemos encontrar en la Red. Adjudicar un hijo a un personaje famoso que acaba de fallecer, confundiendo a lectores, internautas y, si se tercia, a profesionales de los medios de comunicación, es crear un bulo. Hay quién lo hace por entretenimiento y quién se lo toma como un auténtico desafío: a ver quién consigue "colar" el engaño más grande.

Uno de los más grandes, al menos por el tamaño del protagonista, y también por la importancia del medio "engañado" es el del falso Bigfoot. En el verano de 2008 (los responsables de publicar la información debieron haber sospechado algo, aunque sólo fuese por la fecha en que la noticia salió a la luz) Rick Dyer y Matt Whitton (un policía que, por cierto, perdió su trabajo por participar en esta astracanada) aseguraron haber hallado el cuerpo de Pie Grande el mítico sasquatch de las montañas, buscado en Estados Unidos y Canadá desde 1971. CNN se apresura a publicar: "El cuerpo prueba que no es un mito, aseguran los cazadores " (CNN, 2008/1) y explican con más detalle que "Los análisis de ADN ya han comenzado" y que "Un biólogo molecular, un antropólogo y un paleontólogo realizarán extensos estudios al cuerpo" No hicieron falta análisis de AND ni exámenes científicos similares, una semana después de hacerse pública la noticia Dyer y Whitton se veían obligados a confesar la verdad ante la magnitud que estaba alcanzando su "descubrimiento". Era sólo " $a$ big joke" (una gran broma) dijeron, que se les había ido de las manos, convirtiéndose "en algo más grande de lo que debía" (CNN, 2008/2)

Expertos en bulos son los responsables de El Mundo Today (una web de humor con canal de televisión y suplemento dominical incluidos) Un paseo por su sitio web basta para darse cuenta del tono de sus reportajes: "Cataluña será independiente el primer domingo de cada mes", "Hacienda advierte de que las niñas bonitas también pagarán dinero" o "El cártel colombiano traficará con droga sin gluten" son algunos de sus titulares. Puede parecer imposible que alguien los tome en serio, pero no es así. 
El diario 20 minutos se llegó a hacer eco de una de sus noticias, en concreto, sobre el último proyecto del diseñador Adolfo Domínguez. "El Mundo Today" había destapado el asunto: "Adolfo Domínguez diseñará el nuevo uniforme del Ku Klux Klan". Hoy, en lugar de la desafortunada noticia, podemos encontrar las disculpas del periodista. Todo un gesto, por cierto, teniendo en cuenta que lo habitual en este tipo de pifias es eliminar el artículo y actuar como si nada hubiera sucedido. (20 MINUTOS, 2009) Lo que nos permite hacernos la siguiente pregunta que ya nos hemos planteado: ¿Son los recursos web, siempre y en todo lugar, una fuente de información? Los creadores de El Mundo Today no lo pretenden, su vocación es otra, la de hacer reír parodiando a los medios de comunicación tradicionales. Y aquellas web que sí pretenden ser fuentes de información ¿qué requisitos deben tener?

\subsection{La enciclopedia ¿de todos?}

Uno de los fenómenos con más seguidores, defensores, admiradores y también detractores de los últimos años son las páginas de escritura colaborativa: las Wikis. La más conocida de todas ellas es Wikipedia. Para muchos, el maravilloso compendio en el que puede encontrarse todo cuanto uno necesita saber en el mundo, para otros un enorme vertedero informativo en el que separar grano de paja es tan difícil como atravesar un campo de minas.

Su funcionamiento es sencillo: cualquiera puede escribir un artículo sobre un tema que no figure en sus "páginas" o corregir el contenido de alguno redactado previamente por otro usuario. El registro es sencillo, innecesario, incluso, si lo que deseas es simplemente corregir. Así de sencillo, y sobre todo, de anónimo. Wikipedia confía en una lógica de edición sencilla y, en teoría, efectiva: basta el gran volumen de internautas -410 millones de visitantes únicos al mes según datos de noviembre de 2010- (DELCLÓS, Tomás, 2010) que pueden llegar a leer sus artículos a diario para que un error no permanezca publicado demasiado tiempo.

La gran pregunta en lo referente a Wikipedia es si podemos confiar en sus contenidos. Como usuarios, pero, sobre todo, como periodistas que buscamos información con la que confeccionar nuestros reportajes. En este sentido debemos decir que la Wikipedia tiene fieles seguidores en todo el mundo que, de hecho, sólo en 2010, han llegado a donar 16 millones de dólares (12,3 millones de euros) para apoyar su mantenimiento y desarrollo (Delclós, 2011) pero también enemigos confesos. Es el caso, por ejemplo, de Dan Tynan y Sam Vakning, autores de polémicos artículos en los que critican la estructura, funcionamiento y errores de la web. Tynan cuestiona los utópicos valores de libertad, igualdad y participación, de los que presume la enciclopedia online: 
Por sus intrigas fraticidas y sus luchas por el poder, Wikipedia hace que el Vaticano parezca una tertulia en un café. Esta enciclopedia, que aparentemente cualquiera puede editar es, de hecho, una wiki-ocracia donde los expertos luchan por el control [...] Cuestione los Wiki-métodos o su fiabilidad y será fulminado por un Wiki-fan. Viole su código y será castigado (Tynan, 2010)

Tynan se refiere, en parte, a la persecución que ha sufrido el psicólogo y escritor Sam Vakning desde que decidiese criticar la falta de fiabilidad de Wikipedia con su artículo "Los seis pecados de Wikipedia" (Vaknin, 2006). Todo rastro de su obra fue eliminado, y, según denuncia Vakning, nadie puede intentar siquiera volverlo a escribir. Algo que, a juzgar por lo que opina del polémico sitio web, (que es opaca, anárquica, anima a la imprudencia, recompensa la violencia virtual y desprecia el conocimiento real) no debe importarle demasiado, porque es el enemigo más combativo e insistente que tiene, hoy por hoy, la popular enciclopedia. Tienen razón quienes desconfían de Wikipedia.

$\mathrm{Su}$ sistema de edición, es imperfecto, a veces se cuelan errores, y otras se mete la pata hasta el fondo. Una hora antes de conocerse el nombre del Premio Nobel de Literatura de 2010, en Wikipedia ya le habían adjudicado el premio al sueco Tomas Tranströmer (el premio fue, finalmente, para Mario Vargas Llosa); Y no sólo se pueden cometer equivocaciones accidentales, en febrero de 2009 el barón Zu Guttenberg asumía la cartera de economía en el Gobierno alemán y alguien modificó su artículo de Wikipedia para introducir, entre sus nombres de pila, el de Wilhelm (Guillermo) ese mismo día aparecía con ese nombre en las noticias de numerosos medios de comunicación. (BITACORAS.COM, 2011).

Simplemente por el placer de poner a prueba a una de las web más consultadas por periodistas de todo el mundo, aunque lo nieguen y se rasguen las vestiduras si alguien osa siquiera insinuarlo, como parte de esta investigación, decidimos introducir algunos errores en Wikipedia. Uno de ellos en la lista de los Reyes Godos que recoge una tabla publicada en el artículo concerniente a los Reinos de la Península. (WIKIPEDIA, 2010/1) Los tres primeros reyes de la lista original eran Ataulfo, Sigerico y Walia, que reinaron entre los años 410 y 415, en 415 y entre 415 y 418 respectivamente. La lista modificada presenta, desde junio de 2010 y sin que nadie haya notado la diferencia hasta la fecha (1 de septiembre de 2011) el orden alterado.

Walia es, ahora, el primero de la lista, entre el año 410 y el 415, le sigue Ataulfo, que reinó, según esta tabla adulterada en 415 y cierra la lista Sigerico, Rey de los Godos, ahora, entre 415 y 418.1 año y 3 meses y ni un solo comentario alertando del fallo. 
Exactamente lo mismo sucedió con la segunda pifia. Modificamos la filmografía de Frank Borzage para incluir una película que nunca dirigió, "La indeseable" de 1932, obra de un director contemporáneo, Frank Lloyd. Tampoco nadie parece haber notado la diferencia. (WIKIPEDIA, 2010/2)

En busca de un error más aparatoso, una semana después de introducir los anteriores, decidimos cambiar la filmografía de Pedro Almodóvar, dando por sentado que, por ser un director de nuestro tiempo y su cine infinitamente más popular que la lista de los Reyes Godos y la filmografía de Borzage, no pasarían ni cinco minutos antes de que un bibliotecario de Wikipedia corrigiese el error y terminase con nuestro juego. Incluimos "La Comunidad", una película de Alex de la Iglesia, entre los títulos dirigidos por el internacional manchego, concretamente entre "Todo sobre mi madre" y "Hable con ella". El error pasó desapercibido exactamente 7 días antes de que alguien lo descubriese y modificase el artículo. Hoy no queda rastro de nuestro tercer engaño. (WIKIPEDIA, 2010/3)

En el día a día de un periodista Internet puede ser solución y fuente de problemas casi en la misma medida. No podemos negar que es una herramienta útil en nuestro trabajo. Que, como dice Concha Edo, ya nada es igual desde que apareció en nuestras vidas: "Está removiendo el diseño, los contenidos, los géneros, los temas y las secciones [...] y, sobre todo, la relación del medio con los lectores, radioyentes y telespectadores" (Edo, 2002)

Pero tampoco debemos dejarnos llevar por el entusiasmo de habernos cruzado con algo tan aparentemente maravilloso en nuestro camino. Prisioneros del frenesí tecnológico podríamos asegurar que Internet todo lo cambia, y que, puesto que uno de los aspectos de nuestra vida que más se ha transformado desde su llegada es la comunicación, no debemos mostrarnos reacios a redefinir los parámetros de la profesión periodística. La mayoría de los profesionales de la información opina, en cambio, que sería un error.

Debemos recuperar la esencia y los orígenes de la profesión que hemos abandonado en los últimos años, con el resultado de una escandalosa pérdida de credibilidad y el desprestigio en la sociedad (Iglesias, 2011)

Nuestro papel es más importante que nunca: en un mundo en el que hay demasiada información, son los grandes medios de comunicación, los profesionales, los que marcan la diferencia (Altares, 2010)

El sustrato del buen periodismo no cambia con la tecnología. [...] Los grandes valores del periodismo no caducan. Al revés, el nuevo periodismo es más exigente. Su público, también (Varela, 2011) 
Los valores clásicos del periodismo, la imparcialidad y la búsqueda de veracidad que distinguen, sobre el papel, a periodistas de pseudocomunicadores son más necesarios que nunca. En nuestra mano está que dichas cualidades abandonen el campo de la teoría y se instalen en el de la práctica. Nos lo exigen los nuevos tiempos porque hoy, más que nunca, la sobreabundancia de contenidos, el ruido informativo e Internet nos exigen un esfuerzo doble: las nuevas tecnologías no nos colocan al borde de la extinción, nos dan la oportunidad de demostrar que, hoy más que nunca, la sociedad necesita periodistas profesionales y comprometidos.

\section{REFERENCIAS}

A la carta: Telediario 2 - 13/01/10. (2010). RTVE.es. Recuperado el 25 de junio de 2011, de http:// www.rtve.es/alacarta/videos/telediario/telediario-2-13-0110/668073/\#

A la carta: Corazón - 17/01/11. (2011). RTVE.es. Recuperado el 25 de junio de 2011, de http:/ / www.rtve.es/alacarta/videos/corazon/corazon-17-01-11/989960/

A la carta: Corazón - 18/01/11. (2011). RTVE.es. Recuperado el 25 de junio de 2011, de http://www.rtve.es/alacarta/videos/corazon/corazon-18-01-11/991064/\#

Asne. (1998). Editors group realeases preliminary journalism credibility study. Recuperado el 1 de Julio de 2011, de http://asne.org/kiosk/ news/98jcp.htm

Boczkowski, P. (2010). News at work: Imitation in an age of information abundance. Chicago: University of Chicago Press.

Body proves Bigfoot no myth, hunters say. (2008). CNN. Recuperado el 10 de mayo de 2011, de http:/ / edition.cnn.com/2008/US/08/14/bigfoot.body/index.html

Bigfoot hoaxer say it was just a big joke. (2008). CNN. Recuperado el 10 de mayo de 2011, de http://edition.cnn.com/2008/US/08/21/bigfoot.hoax/

Cronología de los Reinos Peninsulares. (2010). Wikipedia. Recuperado el 1 de septiembre de 2011, de

http://es.wikipedia.org/wiki/Anexo:Cronolog\%C3\%ADa_de_reinos_en_la_Pen\%C 3\%ADnsula_Ib\%C3\%A9rica

Curran, J. (2010). The future of Journalism. Journalism Studies, 11(4): 464-476.

Delclós, T. (2011).Wikipedia, 10 años y 278 ediciones. Ciberpaís (El País).

Recuperado el 1 de septiembre de 2011, de

http:// www.elpais.com/articulo/Pantallas/Wikipedia/anos/278/ediciones/elpepi $\underline{\text { rtv/20110111elpepirtv_2/Tes }}$ 
Diaz Nosty, B. (2011). Vida más allá del papel. Telos. Cuadernos de Comunicación e Innovación, 86. Recuperado el 1 de septiembre de 2011, de http:// sociedadinformacion.fundacion.telefonica.com/seccion=1268\&idioma=es_ES \&id=2011012509430001\&activo=6.do\#

Diezhandino, M. P. (2007) Periodismo en la era de Internet. Barcelona: Ariel para Fundación Telefónica.

Edo, C. (2002). Del papel a la pantalla. La prensa en Internet. Sevilla: Comunicación Social.

Edo, C. (2003). Periodismo informativo e interpretativo. Sevilla: Comunicación social, ediciones y publicaciones.

ETA hiere al escolta de un edil del PSE al colocar una bomba lapa en su coche. (2007). 20 minutos. Recuperado el 18 de noviembre de 2010, de http://www.20minutos.es/noticia/288203/10/escolta/herido/atentado/playlist.x $\underline{\mathrm{ml} / \text { playlist.xml/?323 }}$

Filmografía de Frank Borzage. (2010). Wikipedia. Recuperado el 1 de septiembre de 2010, de http://es.wikipedia.org/wiki/Frank_Borzage

Filmografía de Pedro Almodóvar. (2010). Wikipedia. Recuperado el 1 de septiembre de 2010, de http://es.wikipedia.org/wiki/Pedro_Almod\%C3\%B3var

Iglesias, M. (2011). El periodismo de calidad. Telos. Cuadernos de Comunicación e Innovación. Recuperado el 1 de septiembre de 2011, de

http:// sociedadinformacion.fundacion.telefonica.com/seccion=1268\&idioma=es_ES \&id $=2011012611210001$ \&activo $=6$. do

La práctica periodística en los nuevos medios. (2010). Cuadernos de periodistas, 21.

Los gazapos más sonados de la Wikipedia. (2011). Bitacoras. Recuperado el 1 de septiembre de 2011, de http://www.abc.es/20110114/medios-redes/abci-gazaposwikipedia-201101131919.html

Mencher, M. (2003). News reporting and writing. Madrid: McGraw-Hill.

Pido disculpas a Adolfo Domínguez y a los lectores. (2009). 20 minutos. Recuperado el 18 de noviembre de 2010, de http:// blogs.20minutos.es/manolosaco/2010/02/20/pido- disculpas-adolfodomaanguez-y-los-lectores/ 
Tuchman, G. (1983) La producción de la noticia. Estudio sobre la construcción de la realidad. Barcelona: Gustavo Gili.

TVE emite imágenes falsas del terremoto de Haití. (2010). El País. Recuperado el 9 de agosto de 2011, de

http://www.elpais.com/articulo/sociedad/TVE/emite/imagenes/falsas/terremot o/Haiti/elpepugen/20100114elpepusoc_11/Tes)

Tynan, D. (2010). Faith in numbers: six more tech cults. Tech cult $n^{\circ} 3$ : The High Priest of Wikipedia. Infoworld. Recuperado el 1 de septiembre de 2011, de http://www.infoworld.com/d/adventures-in-it/faith-in-numbers-six-more-techcults-846?page $=0,2$

Vaknin, S. (2006). The six sins of the Wikipedia. American Chronicle. Recuperado el 1 de septiembre de 2011, de http:/ / www.americanchronicle.com/articles/view/11109

Varela, J. (2011). Periodismo mutante. Telos. Cuadernos de comunicación e innovación, 86. Recuperado el 1 de septiembre de 2011, de

http:// sociedadinformacion.fundacion.telefonica.com/seccion=1268\&idioma=es_ES

\&id=2011012610500001\&activo $=6$. do

\section{Rufino Sánchez-Sánchez}

De manera puntual asume, además, labores de coordinación de redacción y corrección de textos en el programa. Su trabajo diario con las fuentes de información y las nuevas tecnologías, y su experiencia anterior en otros medios como Cadena Cope (La Mañana de Federico Jiménez Losantos), Tele 5 (Visto y no visto) o La Sexta (Brigada Policial) son las razones por las que se ha decidido a estudiar el comportamiento de los periodistas en el nuevo escenario comunicativo, sus relaciones con las agencias de información y los problemas derivados del tratamiento de las fuentes. 